\title{
Abnormality of risk factors for atherosclerotic disease among young Japanese aged 19-39 years old: an evaluation of health checkup data
}

\author{
Kemal Sasaki $\cdot$ Aya Yoshida $\cdot$ Hiroshi Ohta $\cdot$ Yoshiharu Aizawa $\cdot$ \\ Akiko Kojima $\cdot$ Hitomi Chiba $\cdot$ Shin Mizuguchi $\cdot$ Tatsunori Ishidzuka • \\ Hiroshi Goto $\cdot$ Chiho Uegaki $\cdot$ Kyuhei Kotake
}

Received: 12 February 2012/ Accepted: 3 June 2012 / Published online: 4 July 2012

(C) The Japanese Society for Hygiene 2012

\begin{abstract}
Objectives Japanese public health policies on the prevention of atherosclerotic diseases have focused on controlling obesity. The aim of this study was to assess the prevalence of abnormality in risk factors for atherosclerotic disease among young Japanese classified according to body mass index (BMI).

Methods Data were obtained from 359 men (mean age $32 \pm 5$ years) and 1,108 women (mean age $33 \pm 4$ years) between 2005 and 2010. Abnormal levels of aspartate aminotransferase, alanine aminotransferase, and/or gamma-glutamyltranspeptidase were considered to indicate liver dysfunction, and abnormal levels of low-density lipoprotein-cholesterol, high-density lipoprotein-cholesterol, and/or triglycerides were considered to indicate dyslipidemia. The cutoff points for high blood pressure (HBP) and hyperglycemia were set as a reference in the high-normal range.
\end{abstract}

K. Sasaki · A. Yoshida - A. Kojima - H. Chiba - S. Mizuguchi ·

T. Ishidzuka $\cdot$ H. Goto $\cdot$ C. Uegaki - K. Kotake

Sagamihara Public Health Center, 6-1-1 Fujimi,

Chuo-ku, Sagamihara, Kanagawa 252-5277, Japan

K. Sasaki $(\bowtie)$

Department of Allergy, Aichi Children's Health and Medical Center, 1-2 Osakada, Morioka-cho, Obu, Aichi 474-8710, Japan

e-mail: kemal-s@umin.ac.jp

H. Ohta

Department of Public Health, Kitasato University School of Medicine, 1-15-1 Kitasato, Minami-ku, Sagamihara,

Kanagawa 252-0374, Japan

Y. Aizawa

Department of Preventive Medicine, Kitasato University School of Medicine, 1-15-1 Kitasato, Minami-ku, Sagamihara,

Kanagawa 252-0374, Japan
Results No significant difference was observed in both sexes in all items among each year. In men, HBP (12.9\%), liver dysfunction (33.9\%), dyslipidemia $(29.9 \%)$, and hyperglycemia $(2.7 \%)$ were observed in the normal BMI group $\left(18.5<\mathrm{BMI} \leq 25 \mathrm{~kg} / \mathrm{m}^{2}\right)$. In women, these abnormalities were observed in both the normal BMI group and lean group.

Conclusions Asymptomatic abnormalities, particularly liver dysfunction and dyslipidemia, were observed in a substantial percentage of subjects without obesity. Therefore, we recommend that the comprehensive public health policy should be directed at all individuals, including the non-obese group, for the early prevention/detection against atherosclerotic diseases.

Keywords Obesity - Dyslipidemia - Liver dysfunction . Atherosclerotic disease $\cdot$ Japanese

\section{Introduction}

Within the context of the need for an anti-obesity initiative, visceral fat has been included as an index in the criteria for metabolic syndrome in the Japanese general population [1]. As such a criterion, visceral fat is defined as an essential factor, which is different from the criteria defined by World Health Organization and American National Cholesterol Education Programs, Adult Treatment Panel III $[2,3]$. The concept of a metabolic syndrome has been established. However, an important problem with the Japanese criteria is the possibility of underestimating the risks for atherosclerotic diseases in individuals who are not obese. A number of cohort studies in the Japanese general population have shown that subjects without abdominal obesity are equally at risk for atherosclerotic disease as individuals 
with abdominal obesity [4-6]. The data from these epidemiologic studies were informative for developing public health planning policies, but older subjects formed the predominant age group in many of the studies. Data from young subjects are valuable for developing a strategy for preventing atherosclerotic disease at an early stage.

The health checkup system in Japan legally requires employers to implement regular health checkups for employees. However, the frequency at which these health checkups occur decreases with decreasing number of employees [7]. The specific health checkup examination designed to counter metabolic syndrome was implemented in Japan in 2008, but the program has been targeting individuals aged 40 years or more. Overall, some Japanese individuals, especially those under 40 years of age, have no opportunity to undergo a regular checkup. To resolve this issue, some public health centers provide medical checkups and health guidance for the younger segment of the population. In the study reported here, we evaluated data obtained from health checkups conducted by a public health center for Japanese individuals aged younger than 40 years.

\section{Subjects and methods}

\section{Subjects}

The subjects enrolled in this study included 359 men and 1,108 women (age 19-39 years) living in Sagamihara City, Kanagawa Prefecture, Japan. The data were collected during health checkups conducted by the Sagamihara Public Health Center from April 2005 to March 2010. We provided the public with information relating to the implementation of this health checkup service through our public relations magazine or on the Internet. Only one set of data for each individual, that collected at the first visit, was used for analysis to avoid any overlap of data. The study subjects accounted for $66.7 \%(1,467 / 2,201)$ of all individuals who underwent the health checkups. No subject was pregnant and regularly seeing a doctor for ischemic heart disease, hypertension, liver dysfunction, dyslipidemia, and diabetes mellitus. Sagamihara City is a typical modern Japanese town and has a population of 700,000, of whom 200,000 are aged between 19 and 39 years.

The data were anonymized without any matching links to personal data. This study was performed in accordance with the recommendations outlined in the Declaration of Helsinki. This research was also in accordance with the ethical guidelines for epidemiological research laid down by the Ministry of Education, Culture, Sports, Science and Technology and by the Ministry of Health, Labor and Welfare. The protocol for this study was approved by the ethics board at Sagamihara City.
Analysis

Each subject was asked to fast the night preceding the medical checkup, which was performed at the health center between 0900 and 1100 hours. The height and weight of each subject were measured with the subject wearing indoor clothes but no shoes and the body mass index (BMI, $\mathrm{kg} / \mathrm{m}^{2}$ ) calculated. A physician measure the blood pressure (BP) with a mercury sphygmomanometer on the right arm of seated subjects after a 5-min rest. Systolic BP (SBP) was recorded at the appearance of sounds, and diastolic BP (DBP) was recorded at the disappearance of sounds (Vphase Korotkov). Blood samples were collected for routine laboratory tests, including aspartate aminotransferase (AST), alanine aminotransferase (ALT), gamma-glutamyltranspeptidase (GTP), total cholesterol, high-density lipoprotein-cholesterol (HDL-C), triglycerides (TG), and fasting blood sugar (FBS). Biochemical measurements were performed at the Health Sciences Research Institute (Yokohama, Japan) using routine laboratory methods. Low-density lipoprotein-cholesterol (LDL-C) was calculated by the Friedewald formula according to the recommendation of the Japan Atherosclerosis Society: LDL-C $=$ total cholesterol - HDL-C - TG $\times 0.2$ [8]. The subjects with a TG level $\geq 400 \mathrm{mg} / \mathrm{dL}$ were excluded from the analysis of LDL-C level.

The cutoff points were lean $\left(\mathrm{BMI}<18.5 \mathrm{~kg} / \mathrm{m}^{2}\right.$ ) versus obese $\quad\left(\mathrm{BMI} \geq 25 \mathrm{~kg} / \mathrm{m}^{2}\right.$ ); high BP (HBP; SBP $\geq 130 \mathrm{mmHg}$ and/or DBP $\geq 85 \mathrm{mmHg}$ ); liver dysfunction [AST level $>40$ IU/L, ALT level $>45$ IU/L, and/or GTP level $>50$ IU/L (men) and >32 IU/L (women)]; dyslipidemia (LDL level $\geq 140 \mathrm{mg} / \mathrm{dL}$, HDL level $<40 \mathrm{mg} / \mathrm{dL}$, or TG level $\geq 150 \mathrm{mg} / \mathrm{dL}$ ); hyperglycemia (FBS level $\geq 100 \mathrm{mg} / \mathrm{dL}$ ). To assess HBP and hyperglycemia from the prophylactic standpoint, the criteria for these measures were set as a reference in the high-normal range defined by the Japanese Society of Hypertension and Japan Diabetes Society [9, 10].

A subject with abnormal values of AST, ALT, or GTP was defined as having liver dysfunction, and a subject with abnormal values of LDL-C, HDL-C, or TG was defined as having dyslipidemia. The following items were regarded as risks for atherosclerotic disorders (RISK): obesity, HBP, liver dysfunction, dyslipidemia, and hyperglycemia. In comparison, among the groups categorized by BMI, items other than obesity were regarded as RISK.

Statistical analysis

The $t$ test or analysis of covariance (ANCOVA) was used to assess the significance of differences as mean values. In ANCOVA, age was used as a covariate, and sequential Bonferroni correction was performed on the result. Logistic 
regression was used to examine the relationship among risks, after adjusting for age. The atherosclerotic risks, such as HBP, liver dysfunction, dyslipidemia, and hyperglycemia, were defined as dependent variables, and the groups categorized by BMI were defined as independent variables. Analyses were performed using SPSS statistics ver. 18 (SPSS, Chicago, IL). A $P$ value of $<0.05$ was considered to be significant. In Bonferroni correction for comparison among the three groups, a $P$ value of $<0.016(0.05 / 3)$ was considered to be significant.

\section{Results and discussion}

Although the data were collected during a 5-year period, no significant difference was observed in both men and women in all items within each year. In men, obesity (33.4\%), liver dysfunction (42.6\%), and dyslipidemia $(38.4 \%)$ accounted for more than $30 \%$ of all conditions. Fifteen percent of the women were lean (Table 1). The proportion of both obese men and lean women in our study is consistent with that observed in subjects in the same-age groups in a recent national demographic survey [11]. However, some other epidemiologic studies performed in subjects belonging to the same age group as our subjects reported slightly different results $[12,13]$; in these two studies, the proportion of men with liver dysfunction observed in workers at a manufacturing company was lower than that in our study. These differences can be explained, at least partly, as being due to socioeconomic factors, including the type of work; in our study, $75.0 \%$ of the male workers belonged to the service sector.

Approximately $65 \%$ of men and $25 \%$ of women had more than one RISK factor. In both men and women, all items showed greater exacerbation in the obesity group than in the normal group (Table 2). When adjusted for difference in age, the obesity group had a significantly higher risk of abnormality in all items involved in atherosclerotic disorders than normal group (Table 3). It is clear that not only obesity but also dyslipidemia and liver dysfunction account for the development of atherosclerosis and other metabolic disorders [4-6, 14]. These results imply that one of the main target groups of the disciplinary health educational program "Hokenshido", which was established to achieve behavior modification, should be young obese Japanese to prevent atherosclerotic disorders.

Some subjects in the non-obese group had RISK factors other than overweight. Liver dysfunction and/or dyslipidemia was diagnosed in $30 \%$ of men with normal BMI,
Table 1 Descriptive statistics of variables associated with the risk for atherosclerotic disorders

\begin{tabular}{|c|c|c|}
\hline Descriptive variables & $\begin{array}{l}\text { Men } \\
(n=359)\end{array}$ & $\begin{array}{l}\text { Women } \\
(n=1,108)\end{array}$ \\
\hline Age (years) & $32 \pm 5$ & $33 \pm 4$ \\
\hline BMI $\left(\mathrm{kg} / \mathrm{m}^{2}\right)$ & $23.9 \pm 4.1$ & $21.3 \pm 3.3$ \\
\hline$\geq 25 \mathrm{~kg} / \mathrm{m}^{2}$ & $120(33.4)$ & $127(11.5)$ \\
\hline$<18.5 \mathrm{~kg} / \mathrm{m}^{2}$ & $15(4.2)$ & $168(15.2)$ \\
\hline $\mathrm{SBP}(\mathrm{mmHg})$ & $114 \pm 13$ & $105 \pm 11$ \\
\hline DBP (mmHg) & $74 \pm 11$ & $67 \pm 9$ \\
\hline $\begin{array}{l}\text { SBP } \geq 130 \mathrm{mmHg} \text { or DBP } \\
\geq 85 \mathrm{mmHg}\end{array}$ & $64(17.8)$ & $52(4.7)$ \\
\hline AST (IU/L) & $23 \pm 9$ & $18 \pm 5$ \\
\hline$>40 \mathrm{IU} / \mathrm{L}$ & $17(4.7)$ & $6(0.5)$ \\
\hline ALT (IU/L) & $32 \pm 22$ & $15 \pm 8$ \\
\hline$>45 \mathrm{IU} / \mathrm{L}$ & $65(18.1)$ & $12(1.1)$ \\
\hline GTP (IU/L) & $41 \pm 44$ & $19 \pm 19$ \\
\hline$>50$ or $32 \mathrm{IU} / \mathrm{L}$ & $138(38.4)$ & $70(6.3)$ \\
\hline LDL-C (mg/dL) & $114 \pm 32$ & $102 \pm 26$ \\
\hline$\geq 140 \mathrm{mg} / \mathrm{dL}$ & $70(19.8)$ & $92(8.3)$ \\
\hline HDL-C (mg/dL) & $56 \pm 14$ & $71 \pm 15$ \\
\hline$<40 \mathrm{mg} / \mathrm{dL}$ & $31(8.6)$ & $10(0.9)$ \\
\hline TG (mg/dL) & $122 \pm 85$ & $66 \pm 36$ \\
\hline$\geq 150 \mathrm{mg} / \mathrm{dL}$ & $92(25.6)$ & $45(4.1)$ \\
\hline FBS (mg/dL) & $90 \pm 13$ & $85 \pm 7$ \\
\hline$\geq 100 \mathrm{mg} / \mathrm{dL}$ & $23(6.4)$ & $33(3.0)$ \\
\hline RISK & $1.40 \pm 1.42$ & $0.33 \pm 0.70$ \\
\hline 0 & $122(34.5)$ & $828(74.8)$ \\
\hline 1 & $85(24.0)$ & $201(18.2)$ \\
\hline 2 & $61(17.2)$ & $48(4.3)$ \\
\hline$\geq 3$ & $86(24.3)$ & $30(2.7)$ \\
\hline
\end{tabular}

Values are presented as the mean \pm standard deviation (SD), or as the number with the percentage in parenthesis

$B M I$ Body mass index, $S B P$ systolic blood pressure, $D B P$ diastolic blood pressure, $A S T$ aspartate aminotransferase, $A L T$ alanine aminotransferase, GTP gamma-glutamyltransferase, $L D L-C$ low-density lipoprotein cholesterol, $H D L-C$ high-density lipoprotein cholesterol, $T G$ triglyceride, $F B S$ fasting blood sugar, $R I S K$ risk for atherosclerotic disorders

and in women, these abnormalities were observed not only in the normal BMI group but also in the lean group. When absolute number of subjects was used to evaluate the risk for atherosclerotic disease, in men, those individuals with abnormal HBP, GTP, and LDL-C levels in the normal BMI group were comparable to that in the obese group; in women, these abnormalities were observed most often in the normal BMI group. These results are supported by previous reports that atherosclerotic and metabolic 
Table 2 Risk for atherosclerotic disorders in subjects categorized by BMI

\begin{tabular}{|c|c|c|c|c|c|c|c|}
\hline \multirow[t]{3}{*}{ Descriptive statistics } & \multirow[t]{3}{*}{ Lean } & \multirow[t]{3}{*}{ Normal } & \multirow[t]{3}{*}{ Obese } & \multicolumn{4}{|l|}{$P$ value } \\
\hline & & & & \multicolumn{2}{|c|}{ Normal vs. lean } & \multicolumn{2}{|c|}{ Normal vs. obese } \\
\hline & & & & $t$ test & ANCOVA & $t$ test & ANCOVA \\
\hline \multicolumn{8}{|l|}{ Men } \\
\hline Age (years) & $27 \pm 5$ & $32 \pm 5$ & $32 \pm 5$ & $<0.001$ & - & 1.000 & - \\
\hline SBP $(\mathrm{mmHg})$ & $110 \pm 7$ & $111 \pm 12$ & $119 \pm 14$ & 1.000 & NA & $<0.001$ & NA \\
\hline DBP (mmHg) & $73 \pm 8$ & $72 \pm 11$ & $78 \pm 11$ & 1.000 & NA & $<0.001$ & NA \\
\hline AST (IU/L) & $18 \pm 5$ & $22 \pm 8$ & $27 \pm 10$ & 0.147 & NA & $<0.001$ & NA \\
\hline ALT (IU/L) & $15 \pm 5$ & $26 \pm 15$ & $45 \pm 27$ & 0.133 & NA & $<0.001$ & NA \\
\hline GTP (IU/L) & $17 \pm 4$ & $38 \pm 44$ & $49 \pm 43$ & 0.221 & NA & 0.078 & NA \\
\hline LDL-C (mg/dL) & $90 \pm 20$ & $109 \pm 32$ & $128 \pm 29$ & 0.063 & 0.566 & $<0.001$ & $<0.001$ \\
\hline HDL-C (mg/dL) & $64 \pm 12$ & $62 \pm 14$ & $49 \pm 11$ & 1.000 & 0.558 & $<0.001$ & $<0.001$ \\
\hline TG (mg/dL) & $74 \pm 30$ & $105 \pm 67$ & $161 \pm 105$ & 0.462 & NA & $<0.001$ & NA \\
\hline FBS (mg/dL) & $87 \pm 8$ & $89 \pm 13$ & $92 \pm 12$ & 1.000 & 1.000 & 0.027 & 0.031 \\
\hline RISK (No.) & $0.07 \pm 0.26$ & $0.86 \pm 1.04$ & $1.84 \pm 1.32$ & 0.026 & 0.227 & $<0.001$ & $<0.001$ \\
\hline \multicolumn{8}{|l|}{ Women } \\
\hline Age (years) & $32 \pm 5$ & $33 \pm 4$ & $33 \pm 4$ & $<0.001$ & - & 1.000 & - \\
\hline $\mathrm{SBP}(\mathrm{mmHg})$ & $102 \pm 10$ & $104 \pm 11$ & $113 \pm 12$ & 0.010 & 0.024 & $<0.001$ & $<0.001$ \\
\hline DBP (mmHg) & $65 \pm 8$ & $67 \pm 9$ & $74 \pm 10$ & 0.343 & 0.879 & $<0.001$ & $<0.001$ \\
\hline AST (IU/L) & $19 \pm 4$ & $18 \pm 4$ & $21 \pm 8$ & 0.009 & NA & $<0.001$ & NA \\
\hline ALT (IU/L) & $15 \pm 6$ & $14 \pm 6$ & $23 \pm 15$ & 0.622 & NA & $<0.001$ & NA \\
\hline GTP (IU/L) & $19 \pm 11$ & $18 \pm 16$ & $30 \pm 36$ & 1.000 & 1.000 & $<0.001$ & $<0.001$ \\
\hline LDL-C (mg/dL) & $90 \pm 22$ & $101 \pm 24$ & $119 \pm 28$ & $<0.001$ & $<0.001$ & $<0.001$ & $<0.001$ \\
\hline HDL-C (mg/dL) & $77 \pm 16$ & $71 \pm 14$ & $61 \pm 16$ & $<0.001$ & $<0.001$ & $<0.001$ & $<0.001$ \\
\hline TG (mg/dL) & $58 \pm 26$ & $63 \pm 27$ & $103 \pm 66$ & 0.306 & NA & $<0.001$ & NA \\
\hline FBS (mg/dL) & $84 \pm 7$ & $85 \pm 7$ & $90 \pm 8$ & 0.031 & 0.094 & $<0.001$ & $<0.001$ \\
\hline RISK (No.) & $0.13 \pm 0.37$ & $0.18 \pm 0.44$ & $0.79 \pm 0.96$ & 0.704 & NA & $<0.001$ & NA \\
\hline
\end{tabular}

$P$ value was calculated by the $t$ test or analysis of covariance, adjusted for age

Values are presented as the mean $\pm \mathrm{SD}$

ANCOVA analysis of covariance, $N A$ no available

disorders are found in normal BMI groups [4-6, 15, 16]. Both the Japanese criteria for metabolic syndrome and the public health policy focus on obesity; consequently, there is the possibility that such abnormalities in the non-obese group will be overlooked. The liver dysfunction and dyslipidemia observed in the non-obese group were impossible to miss, thereby illustrating the necessity for countermeasures against health deterioration in such groups.

Our study has a number of limitations. The subjects voluntarily underwent this health checkup service, which may have caused a selection bias. Secondly, this study laced any consideration of lifestyle. Further studies are required to confirm our results on these factors. We are currently analyzing the contribution of both lifestyle and family history on RISK factors in young Japanese individuals in a different observation period.

In conclusion, we found that RISK factors were observed in a substantial number of young non-obese Japanese subjects. RISK factors other than overweight cause asymptomatic changes which can lead to the development of severe complications. The Japanese public health policy against metabolic syndrome focuses on antiobesity measures/education; however, a comprehensive policy directed at all individuals, including those in the non-obese group, is necessary to prevent an increase in atherosclerotic diseases. 


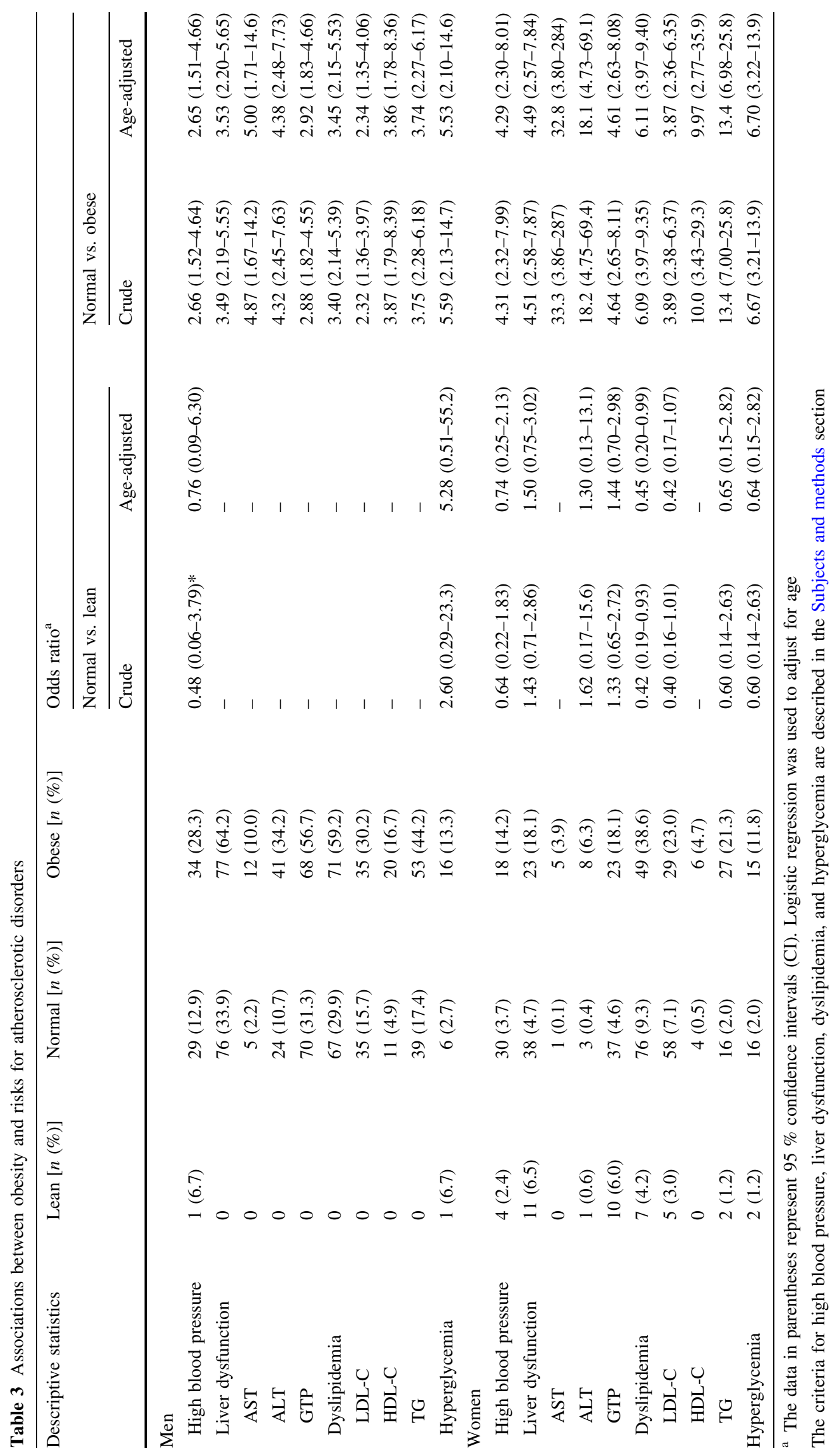




\section{Conflict of interest None.}

\section{References}

1. Oda E, Watanabe K. Japanese criteria of metabolic syndrome. Circ J. 2006;70:364.

2. Expert Panel on Detection, Evaluation, Treatment of High Blood Cholesterol in Adults. Executive summary of the third report of national cholesterol education program (NCEP) expert panel on detection, evaluation, and treatment of high blood cholesterol in adults. JAMA. 2001;285:2486-97.

3. World Health Organization. Definition, diagnosis classification of diabetes mellitus, its complications. Part 1: Diagnosis and classification of diabetes mellitus. World Health Organization, Geneva; 1999.

4. Kadota A, Hozawa A, Okamura T, Kadowak T, Nakmaura K, Murakami Y, et al. Relationship between metabolic risk factor clustering and cardiovascular mortality stratified by high blood glucose and obesity: NIPPON DATA90, 1990-2000. Diabetes Care. 2007;30:1533-8

5. Kokubo Y, Okamura T, Yoshimasa Y, Miyamoto Y, Kawanishi K, Kotani Y, et al. Impact of metabolic syndrome components on the incidence of cardiovascular disease in a general urban Japanese population: the suita study. Hypertens Res. 2008;31:2027-35.

6. Furukawa Y, Kokubo Y, Okamura T, Watanabe M, Higashiyama A, Ono $\mathrm{Y}$, et al. The relationship between waist circumference and the risk of stroke and myocardial infarction in a Japanese urban cohort: the Suita study. Stroke. 2010;41:550-3.

7. Hino Y, Kan H, Minami M, Takada M, Shimokubo N, Nagata T, et al. The challenges of occupational health service centers in Japan. Ind Health. 2006;44:140-3.

8. Friedewald WT, Levy RI, Fredrickson DS. Estimation of the concentration of low-density lipoprotein cholesterol in plasma, without use of the preparative ultracentrifuge. Clin Chem. 1972;18:499-502.

9. Ogihara T, Kikuchi K, Matsuoka H, Fujita T, Higaki J, Horiuchi $\mathrm{M}$, et al. The Japanese Society of Hypertension guidelines for the management of hypertension (JSH 2009). Hypertens Res. 2009;32:3-107.

10. Kadowaki T, Haneda M, Tominaga M, Yamada N, Iwamoto Y, Tajima N, et al. Report of the Japan Diabetes Society's committee on the diagnostic criteria for diabetes mellitus and glucose metabolism disorder - a new category of fasting plasma glucose values: "high-normal". J Jpn Diabetes Soc. 2008;51:281-3.

11. Japan Ministry of Health, Labour and Welfare. The National Health and Nutrition Survey Japan, 2009 (in Japanese). Available at: http://www.mhlw.go.jp/stf/houdou/2r9852000000xtwq-att/2r9 852000000xu3s.pdf. Accessed 12 Feb 2012.

12. Ohwaki K, Yano E. Body mass index as an indicator of metabolic disorders in annual health checkups among Japanese male workers. Ind Health. 2009;47:611-6.

13. Inada F, Moriguchi J, Okuda T, Ide Y, Ejima K, Sakuragi S, et al. Risk for non-obese Japanese workers to develop metabolic syndrome. Ind Health. 2010;48:487-94.

14. Yamada T, Fukatsu M, Suzuki S, Wada T, Yoshida T, Joh T. Fatty liver predicts impaired fasting glucose and type 2 diabetes mellitus in Japanese undergoing a health checkup. J Gastroenterol Hepatol. 2010;25:352-6.

15. Ruderman NB, Schneider SH, Brechtold P. The "metabolicallyobese", normal-weight individual. Am J Clin Nutr. 1981;34: 1617-21.

16. Kishimoto N, Okita K, Takada S, Sakuma I, Saijo Y, Chiba H, et al. Lipoprotein metabolism, insulin resistance, and adipocytokine levels in Japanese female adolescents with a normal body mass index and high body fat mass. Circ J. 2009;73:534-9. 